\title{
Coronary artery thrombus as a risk factor for acute vessel occlusion during percutaneous transluminal coronary angioplasty: improving results
}

\author{
DECLAN D SUGRUE, DAVID R HOLMES JR, HUGH C SMITH, GUY S REEDER, \\ GARY E LANE, RONALD E VLIETSTRA, JOHN F BRESNAHAN, \\ LAVON N HAMMES, JEFFREY M PIEHLER \\ From the Division of Cardiovascular Diseases and Internal Medicine and the Section of Thoracic and \\ Cardiovascular Surgery, Mayo Clinic and Mayo Foundation, Rochester, Minnesota, USA
}

SUMMARY Early experience with percutaneous transluminal coronary angioplasty (from October 1979 to March 1983 inclusive) showed that pre-existing coronary artery thrombus was associated with a significant increase in the incidence of acute coronary occlusion during angioplasty. Acute occlusion occurred in $11(73 \%)$ of 15 patients with pre-existing thrombus compared with $18(8 \%)$ of 223 patients without thrombus. The effect of improved technology (steerable guiding systems) and altered dilatation strategy (full intravenous heparinisation for 24 hours after the procedure and more intensive use of antiplatelet medications) was studied by review of angiograms from 297 consecutive patients without evidence of acute myocardial infarction who underwent angioplasty from April 1983 to March 1985 inclusive. Coronary artery thrombus was present in $34(11 \%)$ patients, eight $(24 \%)$ of whom had complete occlusion during or immediately after the procedure compared with $34(13 \%)$ of 263 patients without thrombus.

Patients with pre-existing coronary artery thrombus continue to be at greater risk of complete occlusion than patients without thrombus, but this risk has declined significantly since the modification of the angioplasty procedure.

Advances in catheter technology and increasing operator experience have improved primary success rates in patients with symptomatic coronary artery disease who are treated by percutaneous transluminal coronary angioplasty. ${ }^{1}$ In a considerable number of patients, however, angioplasty is still associated with serious complication or failure. Complete occlusion of the coronary artery during angioplasty is the most frequent serious complication related to the procedure. Although the occlusion often can be reopened by repeated angioplasty or by anticoagulants, in some patients the occlusion necessitates emergency coronary artery bypass surgery. ${ }^{23}$ In an early series we found that the presence of intraluminal coronary artery throm-

Requests for reprints to David R Holmes Jr, Mayo Clinic, 200 First Street SW, Rochester, Minnesota 55905, USA.

Accepted for publication 18 March 1986 bus before angioplasty predisposes patients to complete occlusion. ${ }^{4}$ Complete and permanent occlusion occurred in $11(73 \%)$ of 15 patients with preexisting thrombus undergoing angioplasty compared with $18(8 \%)$ of 223 patients without thrombus $(p<0.001)$. In the light of this experience the angioplasty procedure was modified by the routine use of steerable systems and heparin and antiplatelet drugs to prevent vessel occlusion. We have assessed whether these modifications have lessened the risk of vessel occlusion in patients with pre-existing coronary artery thrombus who undergo balloon angioplasty.

\section{Patients and methods}

\section{Selection}

Patients undergoing angioplasty at the Mayo Clinic from April 1983 to March 1985 inclusive were identified from a computerised data registry. 

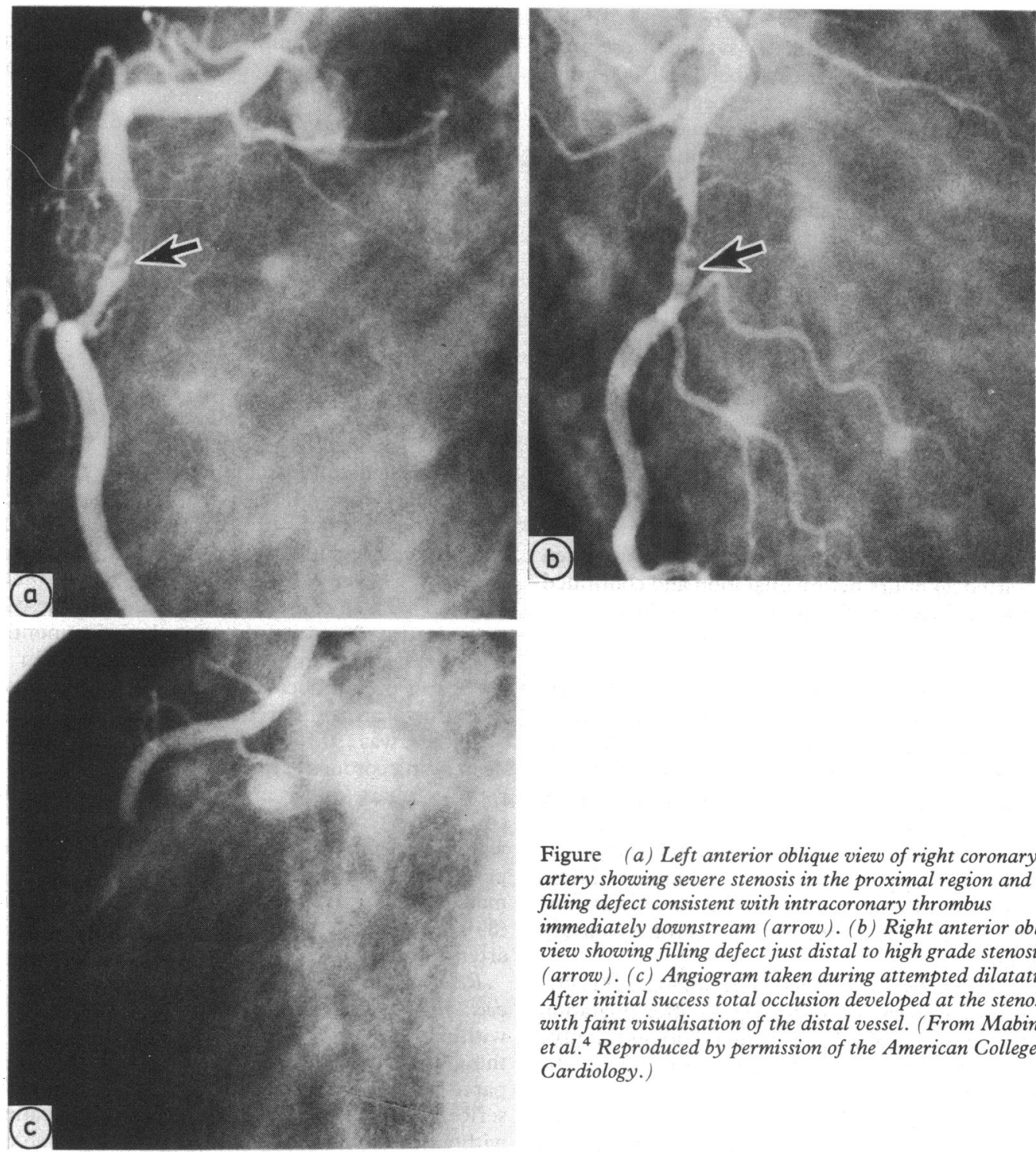

Figure (a) Left anterior oblique view of right coronary artery showing severe stenosis in the proximal region and a filling defect consistent with intracoronary thrombus immediately downstream (arrow). (b) Right anterior oblique view showing filling defect just distal to high grade stenosis (arrow). (c) Angiogram taken during attempted dilatation. After initial success total occlusion developed at the stenosis with faint visualisation of the distal vessel. (From Mabin et al. ${ }^{4}$ Reproduced by permission of the American College of Cardiology.)

Patients who had combined streptokinase infusion and angioplasty during acute myocardial infarction and those with previously occluded vessels were excluded. The remaining 297 patients formed the basis of the study. The presence or absence of intracoronary thrombus before dilatation was determined by two experienced angiographers who were unaware of the outcome of the angioplasty. In a few instances they disagreed and a third opinion was obtained and a majority decision was reached. This evaluation procedure, the criteria for intraluminal thrombus, and the angiographers performing this assessment were the same as those used in an earlier study. ${ }^{4} \mathrm{~A}$ detailed clinical and angiographic profile was available for each patient. Patients with myocardial ischaemia and angiographic lesions suitable for either dilatation or coronary artery bypass surgery were included.

\section{Procedural details}

Details of the angioplasty procedure have been reported. ${ }^{2}$ The current study differs from the pre- 
vious one in several important respects. In the present study, steerable catheter systems were used routinely and all patients received 5000-10000 units of heparin intravenously at the beginning of the catheterisation. In addition, at the end of the procedure an intra-arterial femoral sheath was left in situ, protamine was not used, and full systemic heparinisation by continuous intravenous infusion was continued for 24 hours with careful laboratory monitoring to maintain an activated partial thromboplastin time that was longer than twice the normal values. All patients also received nitrates and calcium antagonists during the angioplasty and afterwards. In addition, an intensive effort was made to treat all patients with an antiplatelet regimen unless this was contraindicated or unless the patients were enrolled in a current continuing prospective placebo control study to evaluate the effects of aspirin and dipyridamole on restenosis. The usual regimen consisted of $75 \mathrm{mg}$ of dipyridamole in combination with $325 \mathrm{mg}$ of aspirin three times daily. This regimen was started 24 hours before dilatation and continued for at least three months after the procedure.

\section{DEFINITIONS}

Coronary artery thrombus - The angiographic criteria for coronary artery thrombus have been described elsewhere ${ }^{5-7}$ (Figure). Criteria included (a) the presence of an intraluminal filling defect surrounded by contrast material and seen in multiple projections, (b) absence of calcium within the defect, and $(c)$ persistence of contrast material within the lumen. The appearance of intraluminal filling defects within the distal part of the vessel was considered to be consistent with a coronary artery thrombus.

Coronary artery dissection-The angiographic criterion for coronary artery dissection after dilatation was the presence of a large intimal flap and double lumen or presence of contrast material within the vessel wall.

Unstable angina-The definition of unstable angina was that used in the National Heart, Lung, and Blood Institute PTCA Registry ${ }^{8}$ : that is, new onset of exertional chest pain, or new onset of chest pain at rest or with minimal effort, or an unexplained increase in the pattern of stable angina pectoris within the preceding two months.

Successful dilatation-A successful dilatation was defined as an increase of $>40 \%$ in the preangioplasty luminal diameter of the stenosis without subsequent coronary artery bypass operation.

\section{STATISTICAL ANALYSIS}

The significance of differences between groups was assessed by use of the Fisher exact test and $\chi^{2}$ test.

\section{Results}

Clinical features-Thirty four patients (26 men and eight women; mean age 58, range 34-77) had angiographic evidence of intraluminal coronary thrombus before angiography (Table 1 ). The mean duration of angina was 20 months (range 1 to 36 ). Two hundred and sixty three patients (163 men and 100 women; mean age 59, range 30-88) did not have a thrombus (Table 1). The mean duration of angina in these 263 patients was 28 months (range 1 to 54 months). There was no significant difference between the groups in the number of patients with previous or recent myocardial infarction.

There was thrombus in the left anterior descending coronary artery in $18(53 \%)$ patients, the right coronary artery in $13(38 \%)$, the circumflex coronary artery in five $(15 \%)$, and in a saphenous vein bypass graft in two (6\%) (Table 2 ). The mean percentage of stenosis of the luminal diameter, estimated from multiple projections, was identical $(89 \%)$ in patients with and those without coronary artery thrombus.

Relation of intraluminal thrombus to acute occlusion-Acute occlusion occurred during or within four hours of the procedure in eight $(24 \%)$ of the 34 patients with coronary artery thrombus, compared with $11(73 \%)$ of 15 patients in the earlier series ( $p<0.01)$, and in $34(13 \%)$ of the 263 patients without thrombus $(24 \%$ vs $13 \%, p=0.17)$ (Table 3 ). Major dissection was not seen in any patient with

Table 1 Clinical details of 297 patients undergoing balloon angioplasty (April 1983-March 1985)

\begin{tabular}{|c|c|c|c|c|}
\hline \multirow[t]{2}{*}{ Characteristic } & \multicolumn{4}{|c|}{ Patients } \\
\hline & \multicolumn{2}{|c|}{ With thrombus* } & \multicolumn{2}{|c|}{ Without thrombus * } \\
\hline $\begin{array}{l}\text { Unstable angina } \\
\text { Variant angina } \\
\text { History of previous myocardial infarction } \\
\text { Recent myocardial infarction ( }<1 \text { mnth) }\end{array}$ & $\begin{array}{r}30 \\
4 \\
19 \\
8\end{array}$ & $\begin{array}{l}88 \\
12 \\
56 \\
24\end{array}$ & $\begin{array}{r}217 \\
11 \\
103 \\
49\end{array}$ & $\begin{array}{r}83 \\
4 \\
39 \\
19\end{array}$ \\
\hline
\end{tabular}

«Determined from angiogram before balloon angioplasty. 
Table 2 Sites of coronary stenosis in patients with and without intraluminal thrombus

\begin{tabular}{|c|c|c|c|c|c|c|}
\hline \multirow[t]{3}{*}{ Site } & \multicolumn{3}{|c|}{ With thrombus (34) $\dagger$} & \multicolumn{3}{|c|}{ Without thrombus (263) $\dagger$} \\
\hline & \multicolumn{2}{|c|}{ Patients } & \multirow{2}{*}{$\frac{\text { Segments }}{\text { No }}$} & \multicolumn{2}{|c|}{ Patients } & \multirow{2}{*}{$\frac{\text { Segments }}{\text { No }}$} \\
\hline & No & $\%$ & & No & $\%$ & \\
\hline $\begin{array}{l}\text { Left anterior descending artery } \\
\text { Circumflex artery } \\
\text { Right artery } \\
\text { Graft } \\
\text { Single vessel disease }\end{array}$ & $\begin{array}{c}18 \\
5 \\
13 \\
2 \ddagger \\
16\end{array}$ & $\begin{array}{r}53 \\
15 \\
38 \\
6 \\
47\end{array}$ & $\begin{array}{r}18 \\
5 \\
15 \\
-\end{array}$ & $\begin{array}{l}155 \\
58 \\
87 \\
10 \$ \\
91\end{array}$ & $\begin{array}{r}59 \\
22 \\
33 \\
4 \\
35\end{array}$ & $\begin{array}{l}171 \\
61 \\
106 \\
-\end{array}$ \\
\hline
\end{tabular}

* Mean percentage stenosis before percutaneous transluminal coronary angioplasty was $89 \%$ in both groups.

$\dagger$ Determined from angiogram before balloon angioplasty.

tOne graft from aorta to right coronary artery and one from aorta to left anterior descending artery.

$\S$ Three grafts from aorta to right coronary artery, three from aorta to left anterior descending artery, and four from aorta to left circumflex artery.

Table 3 Comparison between present series and earlier series

\begin{tabular}{|c|c|c|c|c|c|c|c|c|}
\hline & \multicolumn{4}{|c|}{ Present series } & \multicolumn{4}{|c|}{ Earlier series } \\
\hline & \multicolumn{2}{|c|}{ With thrombus } & \multicolumn{2}{|c|}{ Without thrombus } & \multicolumn{2}{|c|}{ With thrombus } & \multicolumn{2}{|c|}{ Without thrombu } \\
\hline & No & $\%$ & No & $\%$ & No & $\%$ & No & $\%$ \\
\hline $\begin{array}{l}\text { No of patients } \\
\text { Acute occlusion: }\end{array}$ & 34 & & 263 & & 15 & & 223 & \\
\hline $\begin{array}{l}\text { Remained occluded } \\
\text { Reopened } \\
\text { Total }\end{array}$ & $\begin{array}{l}3 \\
5 \\
8\end{array}$ & $\begin{array}{c}9 \\
15 \\
24^{\star}\end{array}$ & $\begin{array}{l}16 \\
18 \\
34\end{array}$ & $\begin{array}{c}6 \\
7 \\
13 \star\end{array}$ & $\begin{array}{r}11 \\
0 \\
11\end{array}$ & $\begin{array}{l}73 \\
73+\end{array}$ & $\begin{array}{r}18 \\
0 \\
18\end{array}$ & 8 \\
\hline
\end{tabular}

${ }^{\star} \mathrm{p}=0.17 ; \mathrm{p}<0 \cdot 001$.

thrombus in whom occlusion occurred. Acute occlusion occurred in $34(13 \%)$ of the 263 patients without thrombus, compared with $18(8 \%)$ of 223 patients without thrombus in the earlier series $\left(\chi^{2}=2.98 ; \mathrm{p}=0.08\right)$. In the 42 patients in whom occlusion occurred, the vessel was successfully reopened non-surgically in $23(54 \%)$; the acute occlusion was successfully reopened by dilatation in five $(63 \%)$ of the eight patients with coronary artery thrombus and in $18(53 \%)$ of the 34 patients without thrombus (NS).

\section{Discussion}

In an earlier study our group reported a very strong correlation between the presence of coronary artery thrombus before angioplasty and the subsequent development of complete occlusion during or immediately after dilatation. ${ }^{4}$ In the present study, although the frequency of complete occlusion was higher in patients with thrombus, this complication was significantly less common $(73 \%$ vs $24 \%)$. Five of the eight patients with thrombus in whom an abrupt occlusion occurred had the vessel successfully reopened non-surgically.

The validity of this study depends on the accuracy of determining the presence of intracoronary thrombus by contrast angiography. The criteria that we used have been validated in surgical and pathological specimens. ${ }^{56}$ Nevertheless, the sensitivity and specificity of angiography for the identification of coronary artery thrombus remain unknown. In a series of 20 patients who had acute myocardial infarction without angiographic evidence of thrombus, thrombi were found at operation in five $(25 \%) .^{5}$ Small thrombi or thrombi adhering to the vessel wall may be difficult to detect angiographically; hence angiography may actually underestimate the true frequency of coronary artery thrombus. On the other hand, the presence of an intraluminal filling defect may not represent a thrombus. ${ }^{910}$

Because this was a retrospective study we can only speculate about the reasons for the improvement in the results. In addition to increased operator experience the exclusive use in the current study of steerable angioplasty systems (which help the operator to negotiate coronary stenoses), the use of continuous heparin infusions for $\mathbf{2 4}$ hours after angioplasty, and the intensive use of antiplatelet regimens seem to be important. We used to give protamine at the end of each procedure to reverse the action of heparin and to ensure adequate haemostasis. Subtle but nevertheless potentially important technical factors that may have contributed to the improved results include optimisation of balloon size, longer observation period in the catheterisation laboratory after 
dilatation, and less stringent criteria for repeat dilatation when the arterial segment appeared to be hazy on the angiogram. The increase in our success rate for reopening acutely occluded vessels is both gratifying and not entirely explicable; steerable angioplasty systems may have been the most important factor.

Although all of these procedural modifications may be exerting a favourable influence on the outcome of dilatation, it is not possible to determine which changes had the most profound impact on these improved results. There was a non-significant increase in the incidence of occlusion in the nonthrombotic group in the current series. This increase may reflect a change in patient selection, in particular a more aggressive dilatation strategy in relatively high risk patients with multivessel disease. Whereas increasing operator experience might be expected to account for some of the improvement in results, the absence of a decline in the incidence of occlusion in patients without thrombus suggests that antiplatelet drugs may have been more important. The optimal dose of aspirin in this setting is unknown, but data from several recent clinical trials suggest that, when given in doses of approximately $1200 \mathrm{mg}$ per day, aspirin exerts a beneficial effect, ${ }^{11} 12$ although a lower dose may suffice. ${ }^{13}$

The mechanism of acute occlusion in patients with intracoronary thrombus in the absence of dissection is also unknown. Potential mechanisms include endothelial damage and platelet deposition; alternatively, the presence of an intraluminal thrombus in the coronary artery may be simply a marker for a hypercoagulable state ${ }^{14}$ or impaired local thrombolysis. Little is known about local in vivo haemostatic mechanisms in the coronary artery at the time of balloon dilatation in patients. Experimental data from the pig angioplasty model support the use of antiplatelet drugs. ${ }^{15}$

\section{CONCLUSION}

Continuous intravenous heparin infusion for 24 hours and use of antiplatelet drugs, possibly in association with the use of steerable angioplasty systems and increasing operator experience, reduced the incidence of complete occlusion in patients with preexisting coronary artery thrombus. Nevertheless, complete occlusion continues to be more common in the presence of intraluminal thrombus. Assuming that the coronary anatomy of patients with stable or unstable angina makes them suitable for angioplasty, we believe that the presence of an intraluminal thrombus itself need not be a contraindication to the procedure. Percutaneous transluminal coronary angioplasty, however, should be undertaken with caution in these patients.

\section{References}

1 Kelsey SF, Mullin SM, Detre KM, et al. Effect of investigator experience on percutaneous transluminal coronary angioplasty. Am $\mathcal{f}$ Cardiol 1984; 53 (suppl): 56C-64C.

2 Vlietstra RE, Holmes DR Jr, Smith HC, Hartzler GO, Orszulak TA. Percutaneous transluminal coronary angioplasty: initial Mayo Clinic experience. Mayo Clin Proc 1981; 56: 287-93.

3 Dorros G, Cowley MJ, Simpson J, et al. Percutaneous transluminal coronary angioplasty: report of complications from the National Heart, Lung, and Blood Institute PTCA Registry. Circulation 1983; 67: 723-30.

4 Mabin TA, Holmes DR Jr, Smith HC, et al. Intracoronary thrombus: role in coronary occlusion complicating percutaneous transluminal coronary angioplasty. f Am Coll Cardiol 1985; 5: 198-202.

5 DeWood MA, Spores J, Notske R, et al. Prevalence of total coronary occlusion during the early hours of transmural myocardial infarction. $N$ Engl f Med 1980; 303: 897-902.

6 Holmes DR Jr, Hartzler GO, Smith HC, Fuster V. Coronary artery thrombosis in patients with unstable angina. Br Heart $\mathcal{F} 1981$; 45: 411-6.

7 Mandelkorn JB, Wolf NM, Singh S, et al. Intracoronary thrombus in nontransmural myocardial infarction and in unstable angina pectoris. $\mathrm{Am} \mathfrak{f} \mathrm{Car}-$ diol 1983; 52: 1-6.

8 Kent KM, Bentivoglio LG, Block PC, et al. Percutaneous transluminal coronary angioplasty: report from the Registry of the National Heart, Lung, and Blood Institute. Am $\mathcal{F}$ Cardiol 1982; 49: 2011-20.

9 Ambrose JA, Winters SL, Stern A, et al. Angiographic morphology and the pathogenesis of unstable angina pectoris. F Am Coll Cardiol 1985; 5: 609-16.

10 Bresnahan DR, Davis JL, Holmes DR Jr, Smith HC. Angiographic occurrence and clinical correlates of intraluminal coronary artery thrombus: role of unstable angina. F Am Coll Cardiol 1985; 6: 285-9.

11 Cairns JA, Gent M, Singer J, et al. Aspirin, sulfinpyrazone, or both in unstable angina: results of a Canadian multicenter trial. $N$ Engl f Med 1985; 313: 1369-75.

12 May GS, Furberg CD, Eberlein KA, Geraci BJ. Secondary prevention after myocardial infarction: a review of short-term acute phase trials. Prog Cardiovasc Dis 1983; 25: 335-59.

13 Lewis HD Jr, Davis JW, Archibald DG, et al. Protective effects of aspirin against acute myocardial infarction and death in men with unstable angina: results of a Veterans Administration Cooperative Study. N Engl f Med 1983; 309: 396-403.

14 Chesebro JH, Fuster V, Pumphrey CW, Wentland B. Improvement of shortened platelet survival half-life from the early to the late phase of myocardial infarction [Abstract]. Circulation 1981; 64 (suppl 4): 197.

15 Steele PM, Chesebro JH, Stanson AW, Holmes DR, Badimon L, Fuster V. Balloon angioplasty: effect of platelet-inhibitor drugs on platelet-thrombus deposition in a pig model [Abstract]. $\mathcal{F}$ Am Coll Cardiol 1984; 3: 506. 